\title{
Percutaneous fluoroscopic gastrostomy catheter placement: is larger better than small bore?
}

\section{Savaş Tepe (*)}

\begin{abstract}
SUMMARY
Aim: To compare the dysfunction and complication rates of small bore and large bore gastrostomy catheters.

Material and Methods: A total of 521 patients (291 males, 230 females, mean age 56 years, range 16-90 years) underwent percutaneous fluoroscopic gastrostomy placement between August 2000 and January 2009. Choice of catheter was based on the preference of the Radiologist. Data was collected retrospectively with institutional review board approval. Radiology reports provided clinical history, indication for gastrostomy, information of the catheter, technical success, and immediate outcome. Post procedural complications and clinical outcomes were obtained.

Results: All catheters were placed successfully. 15 patients with anatomic difficulties for $\mathrm{G}$ tube placement were discarded from the study. Patients who received large bore and small bore catheters were compared. Patients with larger catheters (18F) had fewer short and long term complications and tube dysfunction compared to patients with smaller bore catheters (14F). Discussion and Conclusions: Patients who received small bore gastrostomy catheters were significantly more prone to tube dysfunction. Large bore catheters should be preferred for fewer complications in short and long term.
\end{abstract}

Key words: Fluoroscopy; Interventional; Percutaneous; Stomach; Catheters

ÖZET

Perkutan gastrostomi kateterleri: Büyük olanlar incelere oranla daha mi iyi?

Amaç: Ince ve kalin gastrostomi kateterlerinin disfonksiyon ve komplikasyon oranlarini mukayese etmek amaçlandı.

Yöntem: 521 hastaya Agustos 2000 ile 0cak 2009 arasinda (291 erkek 230 kadin, ortalama yas 56 , yas araligi 16-90) perkutan gastrostomi kateteri yerlestirildi. Klinik bilgi, gastrostomi endikasyonu, kateter secimi, teknik basari ve takipler degerlendirildi. Post prosedur komplikasyonlar ve klinik sonuclar elde edildi.

Sonuç: Kateterler basari ile yerlestirildi. 15 hasta anatomik zorluk nedeniyle calismadan cikartildi. Kalin ve ince gastrostomi kateterleri mukayese edildi. Kalin kateterler (18F) ince olanlara (14F) oranla daha az kisa ve uzun donem komplikasyon ve tup disfonksiyonuna maruz kaldi.

Tartışma: Ince gastrostomi kateterleri tup disfonksiyonuna daha egilimli bulundu. Kalin kateterler erken ve uzun donemdeki daha az komplikasyon oranlarindan oturu tercih edilmelidirler.

Anahtar kelimeler: Girisimsel; Perkutan; Mide; Kateter
Department of Radiology, Bayindir Hospital, Istanbul, Turkey

Reprint request: M. Savas Tepe, M.D., Department of Radiology Bayindir Hospital Bayindir Hastanesi Ali Nihat Tarlan Cd. Ertas Sk. No:17 Icerenköy, Atasehir, Istanbul, Turkey

E-mail: mstepe@bayindirhastanesi.com.tr

Date submitted: 12.03 .2012 • Date accepted: 30.04 .2012 - Online publication date: 28.03 .2013

\section{Introduction}

Percutaneous fluoroscopic gastrostomy has become a well known procedure in today's clinical medicine. It was first introduced to practice in 1983 [1]. Surgical and endoscopic techniques are alternatives. However, the more radiological approach provides ease for patient and clinician, the more popular and preferable it will be compared to the alternative techniques. A study by Duszak and Mabry in 2003 reported that radiologists still perform only a small percentage (7.4\%) of all gastrointestinal access services [1,2]. Previous studies found that when using moderate or large catheters instead of small bore catheters, major complication rates would be fewer therefore using large bore catheters compared to surgical and endoscopic techniques radiologic approach would be equivalent or favorable in terms of success rates, safety and cost $[3,4]$. In this study our results are also in line with these findings.

Trerotola et al [5] suggested the competitive disadvantage associated with the common use of small bore catheters by interventional radiologists. Studies have reported that small bore catheters are prone to tube dysfunctions such as tube occlusion, dislodgement, and pericatheter leakage [6].

In our retrospective study dated between August 2000 and January 2009, we aimed at comparing dysfunction and complication rates of small bore and large bore gastrostomy catheters and presenting the findings.

\section{Material and Methods}

Between August 2000 and January 2009 a total of 521 patients (291 males, 230 females, mean age 56 years, range 16-90 years) underwent percutaneous 
fluoroscopic gastrostomy placement. Patients and results were retrospectively evaluated. Institutional Ethical Committee approval is obtained.

The most common underlying illness necessitating gastrostomy was traumatic brain injury, and following that was cerebrovascular accident. Malignancies represented the third largest group. Enteral feeding was the indication for gastrostomy in $87 \%$ of patients (453 patients). The remaining 13\% patients (68 patients) presented with small bowel obstruction secondary to malignancy requiring gastrostomy primarily for gastric decompression.

Gastrostomy procedure:

Moderate sedation was administered with midazolam and fentanyl. $1 \mathrm{mg}$ glucagon IV was administered for reducing the gastrointestinal system movement. Transverse colon was routinely opacified with barium given a night before the procedure. After gastrostomy procedure the catheter was placed for overnight gravity drainage.

For both small and large bore Gastrostomy procedures, the stomach was insufflated with use of a nasogastric tube placed previously or at the time of the procedure. Local anesthesia was administered at the site of gastric puncture. Three point gastropexy was performed. A stiff guide wire was inserted and the tract was serially dilated to $14 \mathrm{~F}$. Balloon type gastrostomy catheter was placed. The balloon was inflated and secured to the patient. Post placement injection of the tube confirmed a satisfactory position. The gastropexy sutures were cut two weeks after the procedure. (Figure 1.)

Follow up:

Type of catheter placed, indication for procedure, technical success, and immediate outcomes were all

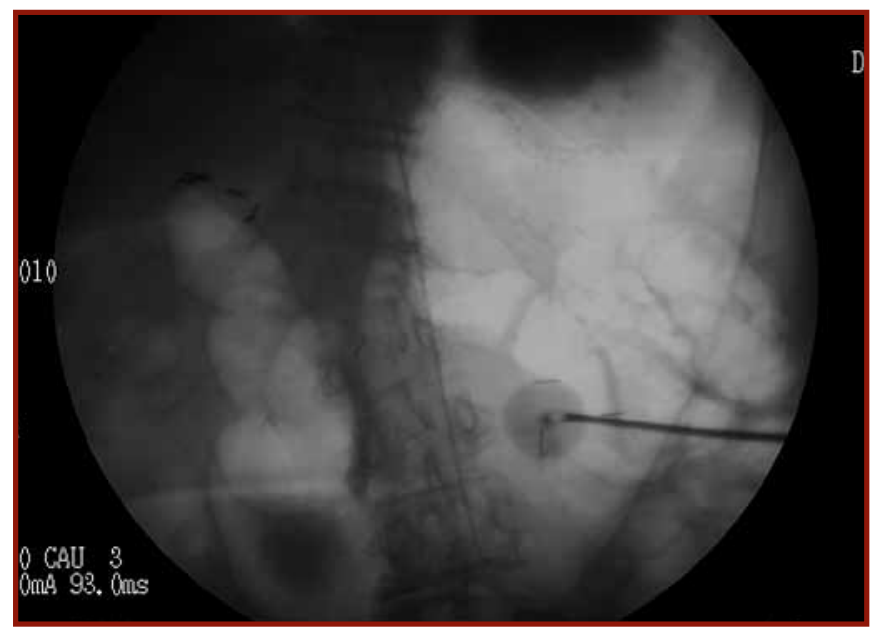

Figure 1. During the Procedure

Well distended stomach with air and three point gastropexy materials are seen. In the middle of the gastropexy triangle an $18 \mathrm{G}$ needle is inserted. In a second a guidewire will go through the needle. Then the needle will be withdrawn and gastrostomy catheter will be placed.

reported for the procedure. Postprocedure complications, discharge summaries, subsequent hospital visits were reviewed.

\section{Major complications:}

Those resulted in a prolonged hospital stay, repeated hospitalizations, adynamic ileus, bleeding requiring transfusions, surgery, pneumoperitoneum (if it is symptomatic and necessitating intervention i.e., a tube change is considered major complication; if not it is considered minor complication ) or death.

\section{Minor complications:}

Local skin cellulites, catheter infections necessitating antibiotic treatment, pneumoperitoneum not necessitating intervention.

Tube complications:

Inadvertent dislodgement, blockage, breakage, pericatheter leakage and other malfunctions.

Table I. Underlying Disease of 521 Patients Undergoing Gastrostomy by Type of Catheter Placed

\begin{tabular}{|c|c|c|}
\hline & $\begin{array}{c}170 \\
\text { patients }\end{array}$ & $\begin{array}{c}351 \\
\text { patients }\end{array}$ \\
\hline Underlying Disease & $\begin{array}{l}\text { Small Bore } \\
\text { (14F G Tube) }\end{array}$ & $\begin{array}{l}\text { Large Bore } \\
\text { (18F G Tube }\end{array}$ \\
\hline Traumatic Brain Injury & $59(34.7 \%)$ & $109(31.1 \%)$ \\
\hline Cerebrovascular Accident (stroke, hemorchage) & $43(25.3 \%)$ & $78(22.2 \%)$ \\
\hline $\mathrm{Head} /$ neck Ca & $19(11.2 \%)$ & $45(12.8 \%)$ \\
\hline Esophageal Ca & $3(1.8 \%)$ & $17(4.8 \%)$ \\
\hline Other Malignancy & $6(3.5 \%)$ & $17(4.8 \%)$ \\
\hline Small Bowell Obstruction & $9(5.3 \%)$ & $20(5.7 \%)$ \\
\hline Failure to thrive & $6(3.5 \%)$ & $19(5.4 \%)$ \\
\hline Other CNS Disorder (Severe Dementia, Alzheimer, Parkinson, ALS) & $25(14.7 \%)$ & $46(13.1 \%)$ \\
\hline
\end{tabular}


30 day mortality was recorded and all causes regardless of whether they were related to the procedure or not were included.

Catheters are usually expected to be problematic after 3 months, and changes are recommended [2] therefore any tube complications after 3 months were not included.

Since many patients were already at a high risk for aspiration at the time of the procedure, it is difficult to objectively ascribe an aspiration pneumonia event to the catheter placement [2]. Therefore aspiration pneumonia was not included as a complication.

\section{Results}

All 521 gastrostomy procedures were performed successfully. Radiology reports provided clinical history, indication for gastrostomy, information of the catheter, technical success, and immediate outcome. Post procedural complications, progress and clinical outcomes were obtained.

15 patients with anatomic difficulties for $G$ tube placement were discarded from the study. Since their stomach did not obtain an ideal position and remained too high for secure gastropexy after insuffilation of air or transverse colon interfered anterior to the stomach, 14 of these cases were excluded from the study at the beginning. One patient had inadvertent abdominal aorta wall puncture during direction of $\mathrm{T}$ fastener needle through the abdominal wall directed at stomach. A crunching sensation was felt to represent the needle tip against a calcified aorta. The patient was observed for several minutes, without return of blood. The needle was injected with contrast but no filling of lumen of aorta was seen. Needle was withdrawn; the patient was stable in condition. This was considered a failed $G$ tube attempt. The patient was followed up more than two years and found in stable condition.

Accidental pulling of the catheters by the patient or falling of the catheter did not differ significantly by the type of the catheter size (39 patients with $14 \mathrm{~F}$ and 35 patients with $18 \mathrm{~F}$ size $\mathrm{G}$ tube accidentally pulled back or fell off).

In 170 patients small bore catheter $14 \mathrm{~F}$ was placed. The mean age for this group was 56 years (range 1890 years). 7 patients experienced major complications (4.1\%). Pneumoperitoneum and abdominal pain requiring repeat intervention were the most common major complications. These occurred between postprocedural days 2 and 5 .

One patient $(0.6 \%)$ had gastrointestinal bleeding episode at the gastropexy site on post procedural day 6 .

Average follow up period was 30 days (range 2-90). Complications occurred during post operative days as in $1^{\text {st }}$ week ( 29 patients, $\left.5.5 \%\right), 2^{\text {nd }}$ week (23 patients $4.4 \%), 3^{\text {rd }}$ week (17 patients $3.3 \%$ ) and later than $3^{\text {rd }}$ week (11 patients $2.1 \%$ ). Complications were grouped as major, minor, or tube complications.

Minor complications occurred in 16 patients (5.4\%).

Tube complications occurred in 38 patients (22.4\%). The majority of these were related to tube displacement or dislodgement between post procedural days 2 and 30.

(26 patients, $15.2 \%) .8$ patients (4.7\%) experienced a clogged catheter between post procedural days 2 and 70 .

Four patients (2.4\%) had pericatheter leak between days 15 to 40 .

All tube complications were treated successfully by replacing the malfunctioning gastrostomy tube and/ or changing to $18 \mathrm{~F}$ tube. In 21 patients catheters were converted to gastrojejunostomy catheter because of the risk of aspiration pneumonia (18 of them were small bore catheters).

351 patients received a large bore $18 \mathrm{~F}$ catheter. Mean age of this group was 56 years (range 16-90 years). No major complications occurred in patients receiving $18 \mathrm{~F}$ catheters.

10 patients experienced minor complications (2.9\%). Two patients $(0.6 \%)$ had skin infection at the gastrostomy site on post procedural day 10 and day 12. These were treated with antibiotics. Another patient presented with bleeding from the catheter site on post procedural day 15 . The cause was thought to be secondary to heparin treatment. The patient recovered after heparin was discontinued and gelatin sponge (Gelfoam, Upjohn, Kalamazoo, Mich) was applied to the wound. There were fewer tube complications with using 18F gastrostomy catheter (total of

Table II. Complication rates of Two Types of Catheters

\begin{tabular}{lcc}
\hline & $\mathbf{1 4 F}$ & $\mathbf{1 8 F}$ \\
\hline Number of Patients & 170 & 351 \\
Major Complications & $7(4.1 \%)$ & 0 \\
Minor Complications & $16(5.4 \%)$ & $10(2.9 \%)$ \\
Tube Complications & $38(22.4 \%)$ & $9(2.6 \%)$ \\
\hline
\end{tabular}


nine - 2.6\%); 8 dislodgment, one clogged catheter. In 8 patients $(2.3 \%)$ catheter was converted to a gastrojejunostomy catheter because of the risk of aspiration pneumonia.

Statistical analysis comparing $14 \mathrm{~F}$ and $18 \mathrm{~F}$ catheters revealed difference in major complication rates. Small bore catheters were associated with a significantly higher incidence of tube complications. The minor complication rate is also higher with smaller size catheters. Superficial cellulites accounted for most of the minor complications.

8 patients died in 30 days, 18 patients died in 60 days secondary to noncatheter related conditions (intracranial bleeding, severe respiratory distress). 30 day mortality rates were similar in both groups.

The small or large bore groups did not differ demographically: There was no statistical association among the type of catheters placed and the underlying disease or indication for gastrostomy.

\section{Discussion}

A result of $95-100 \%$ reported success rate [7] percutaneous fluoroscopic gastrostomy is commonly the preferred method. This study compares the results of small bore $14 \mathrm{~F}$ and large bore $18 \mathrm{~F}$ catheters. Kuo et al [2] compared the small bore, large bore pull and push type catheters, and they indicated that despite the popular use of small bore catheters, they were associated with worst performance among the three classes. For example they showed that tube occlusion occurred only with small bore catheters because of their smaller radius and greater resistance to flow as determined by Poiseuille`s law [6]. Many small bore catheters were also dislodged or displaced. Ultimately the increased risk of tube dysfunction and subsequent catheter replacement bear greater distress and cost for the patient as well as consequently influencing physician's satisfaction and referrals. Therefore the prevalent use of small bore gastrostomy tubes may be a reason for the competitive disadvantage that radiologic gastrostomy faces compared with surgical and endoscopic modalities. Large bore catheters will decrease the time to feeding goal, the patient's hospital stay which reduces cost, hospital related stress, infection, morbidity, and mortality.

Studies suggested that smaller inner diameter of catheters leaves them prone to tube complications such as catheter blockage, displacement, and leakage [6]. Toshinobu et al used $18 \mathrm{G}$ gastrostomy tubes under guidance of CT and fluoroscopy and had no major complications in their series [8].

The conversion to a gastrojejunostomy catheter from a large bore catheter is simple and cost effective. The primary placement of a large bore catheter would obviate removal of the existing tube during gastrojejunostomy conversion [2].

\section{Conclusion}

Our results indicated that either small (14F) or large bore (18F) fluoroscopic gastrostomy demonstrated a high technical success rate and a relatively low complication rate. Lower complications necessitate shorter hospital stay, less hospital related stress and fewer infections, decreased cost, morbidity and mortality. The patients who received $14 \mathrm{~F}$ gastrostomy catheters were more prone to tube complications in short and long term. Large bore (i.e. 18F) catheters had better results, therefore should be preferentially used with regards to their superior long term durability.

\section{References}

1. Duszak R, Mabry MR. National trends in gastrointestinal access procedures:an analysis of Medicare services provided by radiologists and other specialists. J Vasc Interv Radiol 2003; 14: 1031-1036.

2. Kuo YC, Shlansky-Glodberg RD, Mondschein JI, et al. Large or small bore, push or pull: A comparison of three classes of percutaneous fluoroscopic gastrostomy catheters. J Vasc Interv Radiol 2008; 19: 557-564.

3. Wollman B, D`Agostino HB, Walus-Wigle JR, et al. Radiologic, endoscopic, and surgical gastrostomy: an institutional evaluation and metaanalysis of the literature. Radiology 1995; 197: 699-704.

4. Barkmeier JM, Trerotola SO, Wiebke EA, et al. Percutaneous radiologic, surgical endoscopic and percutaneous endoscopic gastrostomy /gastrsojejunostomy: comparative study and cost analysis:Cardiovasc Intervent Radiol 1998; 21: 324-328.

5. Trerotola SO, Shah H, Johnson MS et al. Single step dilation for large bore percutaneous gastrostomy and gastrojejunostomy. J Vasc Interv Radiol 1998; 9: 579-582.

6. Funaki B, Zaleski GX, Lorenz J et al. Radiologic gastrostomy placement: mushroom versus pigtail catheters. AJR Am J Roentgenol 2000; 175: 375-379.

7. Giuliano AW, Yoon HC, Lomis NN et al. Fluoroscopically guided percutaneous placement of large-bore gastrostomy and gastrosjejunostomy tubes:review of 109 cases. J Vasc Interv Radiol 2000; 11: 239-246.

8. Toshinobu T, Takeshi F, Kazumi M, et al. The usefulness of gastrostomy guided by CT and fluoroscopy. Japanese Journal of Clinical Radiology 2002; Vol 47, No $13,1826-1829$. 